\title{
Revisiting the Writing Assessment Process at a Saudi English Language Institute: Problems and Solutions
}

\author{
Abdullah Alshakhi ${ }^{1}$ \\ ${ }^{1}$ English Language Institute, King Abdulaziz University, Jeddah, Saudi Arabia \\ Correspondence: Abdullah Alshakhi, English Language Institute, King Abdulaziz University, Jeddah, Saudi \\ Arabia.
}

Received: September 8, 2018

Accepted: December 20, 2018 Online Published: December 24, 2018

doi: $10.5539 /$ elt.v12n1p176

URL: https://doi.org/10.5539/elt.v12n1p176

\begin{abstract}
Over the past several decades, writing assessment has evolved in an ever-growing attempt to provide contextual fairness to a student while maintaining standards across a larger community. This study analyzed writing assessment at a Saudi English Language Institute (ELI) by first discussing teaching and learning in an EFL context before examining the shortcomings of current Saudi methods in assessment. A universal rubric created by the Saudi ELI allows for consistency across the program and cross-grading between teachers ensures honesty in assessment, but this rigidity leads to a lack of trust between teachers and coordinators and disallows contextual-based learning. First-hand research and literature analysis show that an analytic, rather than holistic, rubric will allow greater contextual-based learning, and that elimination of cross-grading will empower a teacher to become more directly involved with each student. These changes ultimately benefit the students, teachers, and coordinators of the program.
\end{abstract}

Keywords: writing assessment, analytic, holistic, rubric

\section{Introduction}

Writing assessment is rarely a topic of agreement among theorists, practitioners, students, and stakeholders. As educators, we are always curious about how we should assess students' writing, and how we can come to a consensus in that regard. Several inquiries related to language assessment have been aroused, such as What are we trying to accomplish with writing assessment? Which should we choose? Multiple-choice tests, timed essays, portfolios, standardized tests, or no assessment at all? Ultimately, the decision of choosing the most appropriate assessment should align with the goals and visions of the targeted program. Every aspect has to be contextualized in order to obtain meaningful consequences of our decisions. Ovando and Combs (2018) believe that context influences the decisions we make as teachers. We consider viable teaching methods and how they align with the program or course and correspond with the school's mission. White (1985) also discussed how an assessment device is neither good nor bad, only in relation to the context in which it is situated. Assessments would be futile if the context was never considered.

Based on these valuable arguments, the present paper investigates the context of the writing assessment procedures at an English Language Institute (ELI) at a Saudi University. First, I will examine teaching and learning writing skills in the English as a Foreign Language (EFL) context and then, more specifically, in the Saudi Arabian context. Following that, I will explain how writing is taught and assessed in the Saudi context. Next, I will present the writing assessment pitfalls in relation to the Saudi context of which I consider a shortcoming for students' abilities to improve their writing. Finally, I will discuss alternative assessment tools that, I believe, will foster a better approach to writing assessment at the Saudi ELI.

\section{Literature Review}

\subsection{Writing Assessment Studies in EFL Contexts}

Since the English language has grown rapidly as a lingua franca, English courses are required in most EFL settings (Dang, Nguyen, \& Le, 2013). In Saudi Arabia, the only foreign language taught in K-12 and in higher education is English (Moskovsky \& Picard, 2018). The medium of educational instruction is Arabic, but as Al-Seghayer (2005) indicated: "English is used as the medium instruction in most university technical departments and in science, medicine, and engineering" (p. 2). Additional European languages are only taught at 
the university level for students who wish to join a European languages concentration, such as French. Unless a student is involved in these language concentrations, the only foreign language offered to students in the Saudi educational system is English. Therefore, the need for improving students' English proficiency is high.

The four English language skills are taught in schools and at universities in the Saudi education system, but these skills are not treated with equal degrees of importance. For instance, writing is not one of the language skills that curriculum designers give much attention to, and the assessment of students' writing skills is treated much like an afterthought. Ansari (2012) noted that more than 50\% of Saudi EFL students do not know how to write in English, and Al-Khasawneh and Huwari (2013) found that Saudi learners encounter several challenges in English language writing. Therefore, we need to know and understand these challenges in order to find a solution. A writing assessment will not have any effect or purpose if our practices are meaningless and do not contribute to students' learning, in which it must be contextually based. As writing is a major part of the modern global society, curricula must adapt and account for this valuable skill. Students must be well-equipped for modern society, which requires schools and programs to evolve.

There are numerous practices for teaching writing effectively. However, we must approach learning about such practices by first understanding that they were all contextually created and proven successfully in certain contexts. Such practices include the Product Approach. According to Badger and White (2000), the Product Approach focuses on teaching writing structures and practical skills, which are the mainstream applications for English writing classes in EFL. Writing development, Hyland (2003) believed, is thought to be the outcome of structurally or rhetorically imitating and manipulating models provided by the teacher (p. 3). To further this argument, consider Schultz (2001) conclusion that a goal-driven approach in the EFL context rarely provides students with the opportunity to write from their own imaginations because they are directed to practice their language skills in predefined formats (p. 94). In other words, instead of connecting themselves with their writing, students tend to focus on the topical issues of writing, such as grammar, punctuation, and spelling. This is very apparent in Saudi EFL classrooms today.

Take my own experience, for example: I started learning EFL in the seventh grade. Writing in English was one of the most challenging skills for me to acquire. I was taught to focus more on the structure of writing and the grammatical rules. Furthermore, there was little attention paid to the variety of topics and genres of essays in order to increase students' knowledge and exploration of the world through writing. As a student, I was frustrated at the lack of exploratory writing. I could not blame my teachers in the intermediate and high school levels for using this teaching method of writing. Instead, I would criticize the curricula, which I concluded, had contributed to students' low writing competence. Hedgcock and Ferris (2013) criticized the traditional product approach in EFL writing because it stands against training students to write in paragraphs that follow certain formulas. When stating the problems and challenges of teaching writing using the mainstream approaches, Raimes (1991) and Leki (2001) brought attention to raising awareness in taking students' or local contexts' needs into consideration. It implies that there are real disparities between the practices in writing classes and students' local contextual needs.

Based on this discussion, it seems that I am against focusing on grammar and sentence structure in EFL writing; this is untrue as it is not advantageous for EFL students. Rather, I am stressing that we should note the importance of taking context into account before designing writing materials and assessment tools for our students because the writing assessments for EFL students are usually problematic due to the lack of contextual understanding (Bacha, 2001). As a result of differences in student culture and background, context in EFL proficiency levels differ since the focus will vary according to contextual needs. Weigle (2002) described these differences in EFL contexts as at lower levels of instruction, writing is often seen as a support skill for practicing the structures and vocabulary taught in class... in such situations test tasks need to be simple and not require students to generate new ideas or come up with their own organizational pattern. (p. 219)

Weigle's argument seems to be directed to lower-level EFL students. However, as students grow and their knowledge of English improves, the context of their learning changes. Once students reach a higher level of language proficiency, it is expected that they will write with more complexity. Assessment of these students focuses heavily on the content of the paper. Clearly, Weigle (2002) argument is appealing, as it is significant to consider language proficiency levels. I must confess that I was a harsh critic of the focus on language structure in EFL writing teaching and assessment-this critique is not valid in some EFL contexts, such as this Saudi ELI on which I am focusing. Students will not be able to write adequately if they do not acquire the working knowledge of language structure. 


\subsection{The Saudi ELI: Writing Assessments and Teaching Writing}

This section focuses on the Saudi ELI's approach to teaching EFL writing, how the ELI construct writing assessments, and how they approach writing assessment grading.

\subsection{How Writing Is Taught in a Saudi ELI}

The Saudi ELI encompasses four academic levels: level one (beginners), level two (elementary), level three (intermediate), and level four (advanced). After taking the placement test, students are assigned to their language levels. The students must study 18 hours of English instruction each week, in which there is a heavy focus on writing. All language skills - listening, speaking, reading, and writing - are taught in an integrated method. In addition, these classes are not specifically geared toward writing but to English language instruction in general. Teachers must follow a pacing guide designed by the Curriculum Unit that has materials and suggested times for teachers' use during the instruction. Students are usually trained to master the needed grammatical rules and related vocabulary that will help them when beginning to write short paragraphs. Surely, every level has its own goals and own needs, but all levels share a common goal: improving students' mechanics and sentence structure. In EFL writing, this is a valid goal as grammatical acquisition is indispensable in learning second language writing (Bachman \& Palmer, 1996; Weigle, 2002).

\subsubsection{Who Designs the Writing Exams and Assessment Tools?}

All ELI materials, including writing assessment materials, are designed by the Academic Development Team (ADT). After the ADT designs the materials, they sit with teachers and coordinators for focus group discussions to review the writing and teaching materials and assessment tools. Teachers are not left out of assessment at the ELI; they participate in designing the assessment tools along with the ADT. Crusan (2010) believed that: "instructors need to regain their control of assessment" (p. 185), advising educators to be in charge of their local classroom because they are the ones who have constant communication and observation of their students. I support Crusan's point of view and I am pleased to report this ELI includes their teachers in the designing and planning of assessments. Based on the feedback the ADT receives, they introduce the materials to a committee for approval, and, in a later stage, for implementation.

The ELI has identical goals and a pacing guide within each language level. Teachers and coordinators sit together to design the assessment tools and teaching materials. I believe that the administrators and the teachers consider the significance of the context and they both work together to design what works for their institution. This is in agreement with what several writing assessment researchers such as Huot (1996), White (1985), Elbow (2012), and Weigle (2002) proposed about investigating the site's needs and goals before designing assessment tools. If the assessment works for the local context, it is then the best choice to implement.

I have nothing against allowing the ADT and the Assessment Unit to design the writing assessment tools. Teachers are involved directly through focus-group discussions, which provides an area for standards to be dependent upon context. Table 1 is the ELI's official writing curriculum, which includes the objectives and writing exams requirements of each level. Because the ELI has an integrated language-skill program, the writing skill is allotted 30 percent of the overall grade. For the other skills-which are not my focus in this essay—reading is allotted 30 percent, listening 20 percent, and speaking 20 percent.

Table 1. Saudi ELI writing curriculum

\begin{tabular}{|c|c|c|}
\hline $\begin{array}{l}\text { Objectives \& } \\
\text { Requirements }\end{array}$ & Objectives & $\begin{array}{l}\text { Writing Exams Instructions } \\
\text { Overall Grade (30\%) }\end{array}$ \\
\hline
\end{tabular}

Content: A series of complete simple sentences forming a

Write basic, simple

Level 1 sentences leading to a paragraph descriptive paragraph, displaying control of appropriate spelling, grammar, vocabulary, punctuation, and Capitalization for this level in legible, neat, and comprehensible writing.

Frequency: Three per module.

Time: 30 minutes.

\section{Level 2}

Write simple cohesive paragraphs on familiar topics
Content: One or two cohesive narrative or descriptive paragraph(s), using facts, opinions, appropriate introduction and flow of events, accurate spelling, appropriate grammatical and lexical range and accuracy for this level in legible, neat, and 
comprehensible writing.

Frequency: Three per module.

Time: 30 minutes.

Produce a range of text types using coherent and Level 3 cohesive paragraphs in an adequately developed response.

Content: Two to three coherent and cohesive paragraphs (descriptive, narrative, or discursive), using facts, opinions, appropriate introduction, supporting details, conclusion, and displaying accurate spelling and appropriate grammatical and lexical range and accuracy for this level in legible, neat, and comprehensible writing.

Frequency: Three per module.

Time: 30 minutes $30 \%$

Content: A coherent and cohesive descriptive, narrative, or discursive essay of at least three paragraphs on a familiar topic,

Construct a range of coherent and cohesive Level 4 texts with multiple paragraphs in a fully developed response using facts, opinions, appropriate introduction, supporting details, conclusion, and displaying accurate spelling and appropriate grammatical and lexical range and accuracy for this level in legible, neat, and comprehensible writing.

Frequency: Three per module.

Time: 40 minutes.

\subsubsection{How Writing Exams Are Conducted}

Three timed essay exams are offered in each level: two midterm exams and one final. Students at all levels are usually given the opportunity to choose from two different prompts to write in a limited time, usually forty minutes. Timed essay tests might seem an unfair assessment tool because students do not experience an authentic writing task or environment; they write one essay in one genre. Writing is a process-oriented practice best suited when completed over time, not under short time constraints, such as timed exams. This direct assessment method has the face validity of a writing exam, but it may struggle in regard to reliability. The rationale for using impromptu essays to assess writing is derived from Weigle (2002) argument. She argues that second language (L2) writing teachers implement timed essay exams for three reasons: first, teachers want to ensure that students are working on their own; second, teachers intend to prepare students for taking the language proficiency test, such as the Test of English as a Foreign Language (TOEFL) or the International English Language Testing System (IELTS); and third, teachers are curious to see students' automatized language knowledge. That is to say. timed essay exams will yield some results in regard to students' command of the language and writing ability.

Students' writing levels at the ELI are generally very low. They need more guided instructions from their teachers and a direct assessment to check their progress. When the ELI attempted to implement portfolio as an alternative and more sophisticated writing assessment method, several pitfalls emerged that caused ELI administrators to shift their attention back to timed essay exams. Students simply did not write their own papers. With the portfolio, students were receiving help from tutors or better student writers causing their homework to be radically different from their in-class exams. After submitting their portfolios, some teachers noticed the discrepancy between students' performances in their portfolios and their scores on the placement tests. It was obvious that students' misunderstanding of the value of portfolio and their frustrations with their low writing abilities led them to find someone else to write their portfolios for them. Instead, the students might have wanted to finish the course requirements and move on to the next level.

\subsubsection{How Writing Exams Are Assessed}

Regarding grading, Barkaoui (2010) found that holistic scoring was widely used in second-language writing assessment. At the ELI, teachers use a prescribed holistic rubric and a prescribed set of error codes to grade students' papers. The holistic rubric is designed locally and has a scale of ten points. However, teachers do not grade their own students. Instead, the writing coordinator assigns other teachers to do so. Each cross-grading group has ten teachers who exchange papers under the supervision of the coordinator. Teachers then return the graded papers to the coordinator who then returns them to the original teachers. The final stage of grading is the cross-checking session. Here, some teachers are asked to check random graded papers from different grading 
groups using a checklist form to ensure grading accuracy. If the teachers find any inaccuracies in a pack of papers, such as failing to follow the holistic rubric or being too harsh or too tolerant, the papers of that section will be re-graded by the coordinator. After this stage, students will receive their graded papers with the holistic rubric report. With this process, unfortunately, teachers will not be able to explain to their students the rationale behind the grade they received. All ELI students have the right to ask for re-grading if they think they deserve higher grades. To do this, the students must fill out an application form in the Students' Affairs Office which is sent to the coordinator to take action. If the student deserves more marks, s/he will receive them, and if not, the coordinator must explain to the student why s/he received such a score based on the prescribed holistic rubric.

With the understanding of how writing is taught and assessed at the Saudi ELI mentioned above, it is time to revisit the current procedure and then decide upon the possible changes and development. In the next section, I will primarily focus on the two main assessment tools at the ELI: the rating scales and the cross-section grading procedure. I will discuss the related literature and then make an informative decision about whether this system works well in the ELI or not.

\section{Revisiting the Current Procedures}

\subsection{The Rating Scales}

The most common rating scale in writing assessment is the holistic rubric and then the analytic rubric. Every rubric has advantages and disadvantages depending on the context, goals of the program, curriculum, and students' level of writing. Based on these items, what are the pros and cons of these two rubrics? First, I'll start with the holistic rubric and offer its advantages and disadvantages according to the key studies and the theorists in this field. Then, I will discuss the various levels of the ELI rubric and examine the practicality of such rigid implementation across all contexts.

\subsubsection{Holistic Rubric}

White (1984) effectively discussed the holistic rubric, and later, he called for holisticism because it has the benefit of being more reliable than an analytical rubric. According to White (1984), judging writing based on multiple features is problematic as opposed to the unitary global scoring, further stating that: "it has made the direct testing of writing practical" (p. 408). In an earlier study, Perkins (1983) reminded us that holistic scoring has more validity and more practicality because this rubric treats writing as a single entity that cannot be separated into smaller components. Moreover, this kind of scoring is suitable for large-scale assessments as it is economic in both time and money (Behizadeh, 2014). The holistic rubric also focuses on the writer's strengths rather than the weaknesses (White, 1985).

On the other hand, a holistic rubric could be problematic for writing assessments (Park, 2015). White (1985) used to be a proponent of the holistic rubric, but he reminded us not to solely rely on it. He mentioned that "we need to define writing more inclusively than our holistic scoring guides, which normally yield no gain scores across an academic year" (p. 266). White (1985) comments about the holistic rubric indicate that there are more problems than agreements in assessment. What works at one time could be proven problematic at a different time. Also, Carr (2000) noticed this deficiency in the holistic rating scale when he stated: "holistic scores provide an assessment of a single construct" (p. 228). Obviously, the holistic scale treats all writing components, such as cohesion, sentence structure, organization, or argument, as one skill. This might be the biggest pitfall of the holistic scale.

\subsubsection{Analytic Rubric}

The analytic rubric measures multiple traits of writing (Estell, Sapp, \& Reeping, 2016). It may be more expensive and time consuming for raters, but the rubric shows several strengths and weaknesses of the writer. Carr (2000) pointed out that the: "analytic scale conflates the information from several constructs" (p. 228). Weigle (2002) supported Carr's (2000) statement, "this rating scale represents the most concrete statement of the construct being measured" (p. 72). In addition, East and Young (2007) studied the effectiveness of the analytic rubric in 30 writing samples of ESL intermediate students, which were graded by two independent raters. Although the study was limited to only two raters, the results showed that the two raters preferred the analytic rating scale because it showed more details about a student's performance. Similarly, Jonsson and Svingby (2007) carried out a text analysis of 75 relevant studies regarding the usefulness of analytic scoring. They found that the rubric was topic-specific and explicit. The rubric also was helpful and promoted students' learning and writing level because it was.

Conversely, White (1984) looked at the analytic rubric from a different angle. He claimed that this rubric was supposed to give rich data about writing, but, according to him, there is no consensus to "separable sub-skills 
exist in writing" (p. 407). This might be the biggest concern about the usefulness and the authenticity of an analytic rubric. If teachers can read their students' papers to look for discrete sub-skills, there is a concern with how valid and reliable their rating in any educational context is. Training and norming sessions may or may not help to increase the validity and reliability of analytic scoring (Lim, 2019).

\subsubsection{The ELI Rubric}

The writing assessment rubrics at the Saudi ELI focus on a five-point analytical scale. Each level has its own rubric for all assessments. Upon review, the ELI focuses on nearly the same areas across each level's rubric; the complexity of each category increases as the level number increases per module. The main areas are structure and length, content and cohesion, grammar and mechanics, and lexical range. For all levels, students must meet or exceed the length requirement (dictated by word count) in order to obtain higher marks (three-points or above) in all other categories. With a cohesive structure between rubrics, students can continue focusing on improving the main areas of their writing - this is a very thoughtful setup between the levels of the ELI. The setup imposes structured learning curricula, which is helpful for teachers and advantageous for students. However, this structure may also be an obstruction for teachers and students alike because it focuses almost entirely on direct features of writing.

Nakamura (2004) conducted an interesting study to compare the nature of holistic and analytic rubrics. He investigated Weigle (2002) adoption of Bachman and Palmer (1996) six qualities of test usefulness: validity, reliability, impact, practicality, authenticity, and interactiveness. Nakamura (2004) noticed that the analytic rubric is more valid because it rates multiple constructs - it has higher reliability, too. As for practicality, the analytic rubric is time consuming and less economic but has a great impact on diagnosing students' level. The analytic rubric is less authentic. Lastly, the interactiveness is not applicable because there is no interaction between the test taker and the test. Nakamura's conclusion was that the analytic rubric is better for ESL teachers to use when scoring papers Bacha (2001) followed the same path, stating that EFL programs and teachers should reconsider the value of analytical rubrics and consider not relying entirely on holistic rubrics (p. 379). Bacha (2001) also brought our attention to the importance of being accurate when deciding whether ESL students are ready to be promoted to a more advanced level or not. For Bachman and Palmer (1996), analytic scoring is more appropriate in EFL programs, which leads me to discuss the ELI's structure of analytical rubrics.

The level one rubric specifically focuses on length, content, grammar, and spelling and punctuation. This rubric is focused on students adhering to, or exceeding, the assignment requirements. To obtain a five-point scores in each category, the student has to write 50 percent more than the minimum word count; comprehensively answer all bullet points of the writing prompt; use the correct tenses, sentence structures, and proper grammar; and demonstrate knowledge and use of course book vocabulary with text that is free of spelling and punctuation errors. This rubric accurately reflects the beginner level at which students would be writing, intertwining basic prompt responses that allow students to focus on the rudimentary functions of English writing.

Level two rubric details the following categories: paragraph structure and length, content and cohesion, lexical range, and grammar and mechanics. At this elementary level, students are required to correctly perform certain grammatical and sentence structures such as using conjunctions or "linking" words. Students are also expected to use expressions and vocabulary found in the course book and present text that is free of errors in tense, subject-verb agreement, and pronouns. This rubric is a bit more rigorous in grammar and mechanics when compared to the level one rubric, appropriately advancing students into more complex English writing.

The level three rubric expands on the same categories found in the level two rubric but fully separates content and cohesion into their own respective categories, emphasizing specifics in each. Level three students must use specific wording that shows understanding of creating cohesion between sentences and ideas such as phrases like "moreover," "it may appear," or "as a result," and the use of demonstrative pronouns and comparatives. The content category stresses that students make no digression from the topic, accurately and fully answering all bulleted items of the writing prompt. As this rubric is an expansion of the level two rubric, the focus is for students to further develop the intermediary writing skills they have accomplished thus far.

The level four rubric details the ELI's final areas of writing comprehension: structure and length, content, lexical range, grammar and mechanics, and cohesion. All elements in these categories are built upon the previous levels, expanding only in rigorousness of cohesion and use of vocabulary found in this level's course book. The differences between this rubric and the preceding level are minimal; the main differentiating factor is the requirement of sequenced ideas and coherent organization. This rubric is lacking in developmental separation from the level three rubric, providing students with little more to achieve. Perhaps the stipulation of obtaining a personal writing voice or innovative responses to the writing prompt(s) would have elevated this rubric, more 
distinguishably separating it from the level three rubric.

There is a clear cohesion between all rubrics, undoubtedly advancing students in the main areas of English writing as they move up the levels of study. The Saudi ELI has certainly dedicated time to create a rubric structure that is interrelated and quite helpful for both students and teachers as it depicts a clear path for students to develop and hone their writing skills. Nevertheless, students are only consistently reviewed on these main areas of writing and are never scored on personal voice or innovative approaches; reviewers must focus on only the items defined in each category, choosing what point level most accurately reflects the student's work. As exams are also cross-graded, there is an added level of sterility to this process.

To elaborate, Hamp-Lyons (1991) believed that a more detailed rubric has higher validity and reliability in measuring second language writing. Since different learners have different writing abilities, even if they are in the same language level, EFL writers need more feedback than native writers because EFL writers lack intuitive understanding. Making students understand what they should work on would definitely help them to improve where their writing skills are lacking. Carr (2000) stressed the importance of applying the analytic rating scale in the EFL context in class writing; exams alone will not have a positive impact on students' writing development. Students should be trained with this rubric to understand its value in order to get the most benefit from it. Hamp-Lyons (1991) addressed Carr (2000) issue a long time ago when she said educators could not afford to have "a disjunction between teaching and assessment" (p. 244). Although this argument is important, EFL teachers treat their teaching practices and assessment tools as two separate entities. As a matter of fact, teaching and assessment are highly interrelated and cannot be separated. Teachers and students need to understand the connection between what is taught in class and how it is assessed.

The ELI's strict rubric structure leaves little room for interpretation, which could very well be their goal. However, it is important to note that this does not allow students much leeway in approach to a skill that cannot be mathematically deduced - the five-paragraph essay is not the be-all end-all, so therefore how can advanced ESL/EFL writing also be deduced in such a manner? Writing assessment grading is tricky in a native language, though it appears that the Saudi ELI has taken dubious measures to ensure all areas are covered. There is still a question regarding their approach to leveled rubrics. Perhaps these are too defined and strict for ESL/EFL students, especially at the more advanced levels. This can be exacerbated when cross-grading further draws the dividing line between a teacher and his/her students.

\subsection{Cross-Grading at the ELI}

The Saudi ELI has a problematic approach in grading (Obeid, 2017; Rajab, Khan, \& Elyas, 2016). As I stated earlier, teachers do not grade their own students' papers. They swap their section's essay exams with colleagues under the supervision of the coordinator who is responsible for monitoring the exchange process. This form of assessment results in a variety of problems. First, teachers may become embarrassed in front of students because they cannot explain the grade a student has received. Second, teachers do not only judge their students' writing, but they may also judge their colleagues; it could create an unhealthy work environment between teachers and coordinators. Third, teachers might feel that the ELI management does not trust them. That is, these teachers have been hired based on their professional and academic experience and qualifications. Fourth, if the ELI administration is aiming to achieve a higher level of validity and reliability, they should first rely on their teachers and the teachers' assessment desires by allowing them the opportunity to look at and review their own students' exams.

Finally, I wish to propose several solutions to solve the problems related to cross-checking and cross-grading. First, teachers should be given the right to grade their own students' papers. Diederich (1974) in his book Measuring growth in English, talked about the importance of responding to students' writing. He mentioned that teachers should rely more on comments, conferences, and discussions with students, not just on exam grades if they want to help their students. Some people might consider Diederich (1974) thought as an idealistic approach, but I believe this is incredibly helpful. My students appreciate it, too, as they have told me that regular conferences with them made writing tasks more doable. Based on such positive feedback, we, as educators, should use conferences as an additional assessment tool rather than the formal assessment as working closely with students has many benefits.

Second, coordinators can conduct a cross-checking session where they choose five random samples from each section in order to accurately reflect the teachers' grading and to ensure they are following the analytic rubric. This approach will minimize the tension between ELI teachers because they will have to be responsible for their section's exams. Coordinators will have the right to check the validity and the reliability of each teacher's grading. 
Third, if a student is not convinced with his/her score in any of the three writing exams, the student can discuss this matter with his/her teacher. If the problem still continues, the student may ask the assessment coordinator to find an anonymous rater to go over the exam paper again. This approach makes more sense and will prove fairer for students as well.

\section{Implications: Alternative Assessment Tools/Practices}

After discussing how writing is taught and assessed at the Saudi ELI, my recommendation is that an analytic rubric should be adopted due to its benefits in comparison to a holistic scale. This is corroborated by the study of Estell, Sapp, and Reeping (2016) (Rajab, Khan, \& Elyas, 2016)). Based on the reviewed literature, my experience, and my observation in the Saudi ELI, I must say it would be wiser if the ELI use a more detailed rubric and avoid cross-grading sessions. Every instructor teaches one section for 18 hours per week. In each class, there are between 20 to 25 students. It would not be hard for teachers to grade this number of students for each exam with a more detailed rubric. Overall, I believe trying a new assessment tool that projects a positive outcome is worth the investment.

In a nutshell, I discussed the significance of the contextual needs in relation to writing assessments. I believe the Saudi ELI has its own specificity, but it shares several characteristics with other ESL/EFL programs around the world. With this contextual understanding, I think a more detailed analytic rubric should be applied to all four levels in the ELI, and teachers should be trained how to use the rubric effectively. The ADT should be responsible for conducting norming sections and grading workshops for teachers for the sake of achieving a better level of reliability and validity. After teachers understand how to assess their students, the teachers should conduct peer assessment sessions with their students. Students should be taught to understand the purpose and significance of this rubric because they have the right to know and understand how their writing is assessed. This is in line with Obeid (2017) study. Moreover, this kind of knowledge benefits students' overall writing experience through greater understanding of errors made and corrections required.

In addition, cross-grading sessions should be avoided. Instead, teachers should be responsible for grading their own students' papers. This would ideally strengthen the discourse community of each classroom, student-teacher relationships, and students' learning outcomes as they would receive the same style of feedback and comments on their assessments as they do for other non-assessment assignments.

Lastly, I believe conducting grading workshops and meetings would be beneficial for both teachers and coordinators. Coordinators may ensure that teachers are assessing student work fairly and normalize a rubric across the department. Through this, teachers may be given greater autonomy in the classroom while still benefiting from a network of other teachers and coordinators who can advise and assist any given teacher.

\section{References}

Al-Khasawneh, F. M., \& Huwari, I. F. (2013). The reasons behind the weaknesses of writing in English among pre-year students' at Taibah University.

Al-Seghayer, K. (2005). Teaching English in the Kingdom of Saudi Arabia: Slowly but steadily changing. Teaching English to the world: History, curriculum, and practice, 125-134.

Ansari, A. A. (2012). Teaching of English to Arab students: Problems and remedies. Educational Research, 3(6), 519-524.

Bacha, N. (2001). Writing evaluation: what can analytic versus holistic essay scoring tell us? System, 29(3), 371-383. https://doi.org/10.1016/S0346-251X(01)00025-2

Bachman, L. F., \& Palmer, A. S. (1996). Language testing in practice: Designing and developing useful language tests (Vol. 1). Oxford University Press. https://doi.org/10.1177/026553229601300201

Badger, R., \& White, G. (2000). A process genre approach to teaching writing. ELT Journal, 54(2), 153-160. https://doi.org/10.1093/elt/54.2.153

Barkaoui, K. (2010). Explaining ESL essay holistic scores: A multilevel modeling approach. Language Testing, 27(4), 515-535. https://doi.org/10.1177/0265532210368717

Behizadeh, N. (2014). Mitigating the dangers of a single story: Creating large-scale writing assessments aligned with sociocultural theory. Educational Researcher, 43(3), 125-136. https://doi.org/10.3102/0013189X145 29604

Carr, N. T. (2000). A comparison of the effects of analytic and holistic rating scale types in the context of composition tests. Issues in Applied Linguistics, 11(2). 
Crusan, D. (2010). Assessment in the second language writing classroom. University of Michigan Press. https://doi.org/10.3998/mpub.770334

Dang, T. K. A., Nguyen, H. T. M., \& Le, T. T. T. (2013). The impacts of globalisation on EFL teacher education through English as a medium of instruction: An example from Vietnam. Current Issues in Language Planning, 14(1), 52-72. https://doi.org/10.1080/14664208.2013.780321

Diederich, P. B. (1974). Measuring growth in English.

East, M., \& Young, D. (2007). Scoring L2 writing samples: Exploring the relative effectiveness of two different diagnostic methods. New Zealand Studies in Applied Linguistics, 13(1), 1.

Elbow, P. (2012). Good enough evaluation: When is it feasible and when is evaluation not worth having. Writing Assessment in the 21st century: Essays in honor of Edward M. White, 303-325.

Estell, J. K., Sapp, H., \& Reeping, D. (2016). Work In Progress: Developing Single Point Rubrics for Formative Assessment. Paper presented at the Proceedings of the American Society for Engineering Education 2016 Annual Conference. https://doi.org/10.18260/p.27221

Hamp-Lyons, L. (1991). Assessing Second Language Writing in Academic Contexts. ERIC.

Hedgcock, J., \& Ferris, D. R. (2013). Teaching ESL composition: Purpose, process, and practice: Routledge.

Huot, B. (1996). Toward a new theory of writing assessment. College composition and communication, 47(4), 549-566. https://doi.org/10.2307/358601

Hyland, K. (2003). Second language writing. Ernst Klett Sprachen. https://doi.org/10.1017/CBO9780511667251

Jonsson, A., \& Svingby, G. (2007). The use of scoring rubrics: Reliability, validity and educational consequences. Educational Research Review, 2(2), 130-144. https://doi.org/10.1016/j.edurev.2007.05.002

Leki, I. (2001). Material, educational, and ideological challenges of teaching EFL writing at the turn of the century. International Journal of English Studies, 1(2), 197-209.

Lim, J. (2019). An investigation of the text features of discrepantly-scored ESL essays: A mixed methods study. Assessing Writing, 39, 1-13. https://doi.org/10.1016/j.asw.2018.10.003

Moskovsky, C., \& Picard, M. (2018). Teaching English in Saudi Arabia. In S. M. A. Alqahtani (Ed.), English as a Foreign Language in Saudi Arabia (pp. 128-145): Routledge. https://doi.org/10.4324/9781315688466-2

Nakamura, Y. (2004). A comparison of holistic and analytic scoring methods in the assessment of writing. Paper presented at the 3rd annual JALT Pan-SIG Conference.

Obeid, R. (2017). Second Language Writing and Assessment: Voices from within the Saudi EFL Context. English Language Teaching, 10(6), 174-181. https://doi.org/10.5539/elt.v10n6p174

Ovando, C. J., \& Combs, M. C. (2018). Bilingual and ESL classrooms: Teaching in multicultural contexts. Rowman \& Littlefield.

Park, S.-K. (2015). The Interplay of Task, Rating Scale, and Rater Background in the Assessment of Korean EFL Students' Writing. English Teaching, 70(2).

Perkins, K. (1983). On the use of composition scoring techniques, objective measures, and objective tests to evaluate ESL writing ability. Tesol Quarterly, 17(4), 651-671. https://doi.org/10.2307/3586618

Raimes, A. (1991). Out of the woods: Emerging traditions in the teaching of writing. Tesol Quarterly, 25(3), 407-430. https://doi.org/10.2307/3586978

Rajab, H., Khan, K., \& Elyas, T. (2016). A Case Study of EFL Teachers' Perceptions and Practices in Written Corrective Feedback. International Journal of Applied Linguistics \& English Literature, 5(1), 119-131.

Schultz, J. M. (2001). Toward a Pedagogy of. Pedagogy of language learning in higher education: An introduction, 2, 93.

Weigle, S. (2002). Assessing writing: Ernst Klett Sprachen.

White, E. M. (1984). Holisticism. College composition and communication, 35(4), 400-409. https://doi.org/10.23 $07 / 357792$

White, E. M. (1985). Teaching and Assessing Writing: Recent Advances in Understanding, Evaluating, and Improving Student Performance. The Jossey-Bass Higher Education Series. ERIC. 


\section{Copyrights}

Copyright for this article is retained by the author(s), with first publication rights granted to the journal.

This is an open-access article distributed under the terms and conditions of the Creative Commons Attribution license (http://creativecommons.org/licenses/by/4.0/). 